\title{
Creative Excellence in the Japanese University: Knowledge-Content-Cognition and Language-Culture-Communication Integrated Global Awareness Learning
}

\author{
Alan Brady, Robert M. Higgins \\ Kwansei Gakuin University, Nishinomiya, Japan \\ Email: aybrady@gol.com
}

Received 14 October 2015; accepted 14 December 2015; published 17 December 2015

Copyright (C) 2015 by authors and Scientific Research Publishing Inc.

This work is licensed under the Creative Commons Attribution International License (CC BY).

http://creativecommons.org/licenses/by/4.0/

(c) (i) Open Access

\section{Abstract}

Barnett (1997) argues that the university has lost its way, but that the world needs the university more than before but for different reasons. He says that the university must clarify a new role in the world and in society, and find a new vocabulary, and a new sense of purpose. The world including the university is faced with what Barnett calls supercomplexity where human frames of understanding, action, and identity are continually changing and being challenged. In this new supercomplex world, the university, Barnett maintains, must take on two roles in particular. Firstly, it needs to compound supercomplexity, thus making the world more challenging than it has seemed. The second role is to enable humans to live effectively in this chaotic world. Internally, says Barnett, the university needs to become a new kind of organization that must, whether it likes it or not, live with uncertainty (i.e. "the uncertainty principle") and at the same time help people to live with and revel in that uncertainty. Creativity, excellence, and excellence in creativity are also uncertain in this new supercomplex world which requires new and innovative ways of framing their interpretations and development in higher education. We focus in this paper on the potential of additional L2 global language English to serve as the medium of effecting an integrated content-knowledge-cognition and language-culture-communication creatively excellent higher education. However, it is our belief and hope that such a higher learning can and should be developed in the $\mathrm{L} 1$ Japanese language as the primary medium of learning and communication. The employment and deployment of CLIGAL in the home L1 Japanese and the globally useful L2 English are necessary for there to be creative excellence across the Japanese higher education curriculum.

\section{Keywords}

Integration, One-World Ontology, Phronesis, 4Cs and 4Ps, Global Awareness 


\section{Introduction: Who the Writers Are and What We Believe}

The writers of this paper are teacher-researchers at a private university in Japan engaged in additional English language medium teaching and learning with students. One writer works in a specialty-area discipline department (sociology), while the other is engaged in teaching and research in the higher education institution's language-culture-communication center. In the sociology department additional (English) language communication and culture study and L1 Japanese language medium content study are basically separated from each other in what Bollinger et al. (2003) describe as a two world ontology of learning. The institutional (i.e. language-culturecommunication center) and departmental mindset and practice(s) with respect to language study and specialtyarea discipline content-cognition study provisions have the latter (prioritized general and specialized content in the L1) largely divorced from the former (marginalized additional language-communication-culture in an L2, English). Related to this separation and compartmentalization are the de-valuation and marginalization of, in some cases concerted opposition to, a connected and integrated language-content liberal and specialized curriculum study.

In the language center the focus of study and learning is directed primarily, if not solely, to additional (English) language learning as an object of study, without, in our estimation, due to consideration of its (additional language) potential and value as relates to its role and responsibility as a medium of and for deep knowledgecontent-cognition study, specialized and or general higher learning. In the sociology department the focus of L1 Japanese language medium study focuses on what Freire et al. have coined the "banking transmission of knowledge.” Both language and content faculty suffer from having expertise in one area (i.e. language-culture-communication), or the other (i.e. content and cognition), but not both at the same time. This situation, in our estimation, does not allow for a more creatively excellent higher learning experience.

It is thus the main premise of this paper that a more interconnected knowledge-content-cognitive and language-culture-communication study can breed excellence in teaching and learning within the context of where the two writers work. This study integration can best be conceived and practiced through the explicit and committed one-world ontology, where the things we think about, and what and how and why of our communication about those things, are inter-connected in the here-and-now (Bollinger et al., 2003). The re-valuation, some might say a rebirth, of a liberal arts curriculum, in integrated language and content study areas (now separated and compartmentalized), is a pre-requisite towards creative excellence in higher education. This rebirth of liberal-general education needs to be based on a valuation of the what but perhaps more importantly the how and why of study (Flyvbjerg, 2001).

We will in Part IV of this paper, propose an integrated teaching-learning and language-content study approach we call CLIGAL (content language integrated global awareness learning). CLIGAL, as we envision it, is pillared on a value-laden one-world philosophy for thought and social three-folding educational foundation. CLIGAL mindset and practice remain largely absent from the systemic university curriculum at our institution, but if instituted in individual classrooms, if not systemically gives hope of improving the total higher educational creative excellence experience for both teachers and learners. It does so by reinvigorating the breadth and depth of liberal arts higher study within the L1 specialized content study areas that exist in sociology and other academic departments at the institution, and also within the additional (English) language study areas both in specialized study departments such as sociology and the language-culture-communication center.

Barnett (1997) argues that the university has lost its way, but that the world needs the university more than before but for different reasons. He says that the university must clarify a new role in the world and in society, and find a new vocabulary, and a new sense of purpose. The world including the university is faced with what Barnett calls supercomplexity where human frames of understanding, action, and identity are continually changing and being challenged. In this new supercomplex world, the university, Barnett maintains, must take on two roles in particular. Firstly, it needs to compound supercomplexity, thus making the world more challenging than it has seemed. The second role is to enable humans to live effectively in this chaotic world. Internally, says Barnett, the university needs to become a new kind of organization that must, whether it likes it or not, live with uncertainty (i.e. "the uncertainty principle") and at the same time help people to live with and revel in that uncertainty. Creativity, excellence, and excellence in creativity are also uncertain in this new supercomplex world which requires new and innovative ways of framing their interpretations and development in higher education.

We focus in this paper on the potential of additional L2 English as a global language to serve as the medium of effecting an integrated content-knowledge-cognition and language-culture-communication creatively excel- 
lent higher education. However, it is our belief and hope that a creatively excellent higher learning can and should also be developed in the L1 Japanese language as the medium of learning and communication. The employment and deployment of a CLIGAL in both the home L1 Japanese and the globally useful L2 English are necessary for there to be creative excellence across the entire Japanese higher education curriculum. A CLIGAL in the L2 can positively and constructively contribute to necessary second order changes in higher education in Japan. CLIGAL in the L2 can be a driver for that change.

\section{Excellence, Creativity, and Thought Development: What Role and Responsibility for and of Additional (English) Language Study}

The Japanese Prime Minister's Commission on Japan’s Goals in the $21^{\text {st }}$ Century (2000) stated in its preface:

Japan is at a major turning point—one might even say a critical point. The advance of globalization and the information-technology revolution call for a world-class level of excellence. Achieving world-class excellence demands that, in addition to mastering information technology, all Japanese acquire a working knowledge of English — not as simply a foreign language but as the international lingua franca. Knowledge of English as the international lingua franca equips one with a key skill for knowing and accessing the world.

Many perhaps most people in Japan, if they have thought about Japan's place in the world and its future at all, would probably agree with the statement above and an argument put forth in the Japan Times article dated Jan, 29, 2014 (Gottlieb, 2014, The confounding case of Japan's creativity crisis). That article maintains that a higher education, aiming to excel in recognizing the importance and then developing creativity, is a prime component, perhaps the most crucial component, of knowing and accessing the world both within and outside Japan. In Japan in recent years the "buzzword" for knowing and accessing the wider global world has been what is termed in Japanese, "global jinzai" which is roughly translated into English as global citizenry or citizenship.

This term has been used to (try to) convince educational institutions, the business community, other realms of social and economic interests in Japan, as well as the general populace, that Japan's present and future vitality, perhaps even its sustainability and survival, critically depends on its people and institutions being more engaged with the world outside Japan, and more than monolingual or mono-cultural. Most people would also probably agree that the ability to know and use English as an additional global language beneficially contributes to the ability to be a global citizen or global nation, and to know and access the wider world.

Crystal (1997, 2003) in English as a Global Language, Seidlhofer (2005) and others argue that the English language has achieved global status as it is present in most if not all the world, this even though it is used or spoken by only 1.5 billion people, roughly only one fifth of the world's entire population. Given those areas of the world, however, where English has (had) a pivotal role in terms of its influence in a great number of social, economic, political, media, banking, travel, science, technology, and communications domains of life locally as well as globally, there is no question, Crystal maintains, that English is indeed a global language. Crystal further says that:

Too many people around the world have found it (English) a useful tool for there to be any serious likelihood of a reversal of this reality, at least not in the near future."

The global reach and presence of English is clearly recognized by the Japanese Prime Minister's Japan's Goals in the $21^{\text {st }}$ Century Commission of 2000-01, Keidanren (2013), which is the umbrella organization of and for business in Japan, local Japanese media (e.g. the Japan Times 2007 article, Japan's Ambivalent English), and media outside Japan such as the Times Higher Education (2000 opinion article), as well as the Japanese Ministry of Education. In the past six years the Ministry has actively promoted a global and international orientation to higher education to include: (a) hiring more non-Japanese faculty, (b) having more global-international study areas in the curriculum, and (c) having a steep increase in university courses taught in English as opposed to a continuation or even increase of classes that focus on English language as a subject of study per se.

Whatever global competence might mean in terms of being educated to be creative, and in the process having an education that excels in that overall goal, it needs to include English as an important additional language learning medium of excellence in (developing) creative thought. To be creative, and to be creatively excellent, can have multiple meanings or interpretations, and when thought of, verbalized, or written in combination—as is the case for this special issue of Creative Education - an even greater variety of meanings and interpretations. 
Excellence can primarily or solely involve, as the Prime Minister's Commission on Japan's Goals for the $21^{\text {st }}$ Century implicitly states, passively and or uncritically knowing and accessing (what is out there in) the world. Excellence embraces the state or being of excelling, going forward and doing one's best, striving for if not always being able to achieve perfection, or being exceptionally able, being worthy of merit, being or thinking or doing superbly. The concept expressed in English as creativity, combined with excellent and applied to education at any level, also invites different ideas and interpretations of what it means to have "creative excellence” in education, or put another way, to conceive of and practice creative excellence in one's teaching as it can affect student learning.

Kao (1996) defines creativity as "the entire process by which ideas are generated, developed and transformed into value.” Gardner (2009) defines creativity as being “about liberating human energy.” Robinson (2009) says much the same (as Gardner) about creativity though he adds that it "is the also process of developing ideas that are original and of value.” Creativity then can mean different things to different people. It can mean being imaginative or inventive or innovative, taking risks and challenging convention(s). It is also about original thinking or producing something that no one before has thought of or come up with. Some people may even believe that creativity only applies to those who have artistic talent(s).

Let us however not perpetuate any myth that creativity, in any of its interpretations or understandings, is mostly or only about special people thinking and or doing special things. Research shows that there is no correlation of personality type associated with creativity or (one's) being creative. Intelligence or the ability to think and better yet think critically, is of itself creative, and any activity that engages intelligence is in and of itself creative. Creativity as intelligent being or thinking or doing, is not only about coming up with big novel innovative ideas or acting upon those novel ideas, but is also about developing practical everyday solutions to everyday problems, at the very least after one has determined that something is or is not a problem and why and for whom. Creativity is associated directly or indirectly with a very wide range of everyday tasks and activities such as organizing time, managing schedules, making decisions, or taking risks. This importance of creativity at a personal and or communal level should not be underestimated. Van Oech (1990) believes that creativity must be recognized as a process involving both what is termed "hard" and "soft" thinking.

One’s "hard” (right brain) thought can be considered artistic whereas one's "soft (left brain) thinking” can be-no pun intended - thought of as judgmental. Truly creative thought must be both soft and hard thinking combined. Edward De Bono (1982) is of the opinion that as humans grow out of childhood they become more affected by what others think, and this he says, can inhibit their creativity. As humans grow older De Bono believes it becomes more difficult for them to think laterally as their thinking patterns become well established, comfortable, perhaps to some extent even predictable.

Vgotsky (2004) takes the view that young children are less richly creative than adults due to the more limited range of their (childlike) knowledge-including that of the world-and what he, Vygotsky (2004) says, is the lower complexity of their cognition. Children, Vygotsky (2004) argues, tend to create or be creative mostly or only for themselves, while adults, he says, are in the habit of creating both for themselves and the world or worlds in which they live. This issue, and this paper in particular, are not primarily interested in different conceptualizations or opinions, academically or theoretically based as they may be, of whether creativity is more a part of being a child and or a part of growing up and becoming adult. What this issue and paper are concerned about is developing creativity in the educating process, and how we educators can help students develop resilience around their creative thoughts and or actions and at the same time help and invite other students to, for example, assess, evaluate, and contribute to individual creative thought or action.

De Bono (1982) further contends that:

We really need to stop considering thinking as simply intelligence in one(s) action, and think of it as a skill that can be developed by anyone.

We believe that thinking and creativity is a composite of skills that we as educators continually need to excel at and develop for students and ourselves as well. The manner in which we do this, and our ongoing commitment to creative thought development in our teaching and students' learning, will be one marker to ultimately determine how we are or are not excelling at creative education in our teaching. To foster creativity in thought and action, De Bono maintains, educators need to develop a skill set for hard and soft thought alike, A post method pedagogy, following Kumaravadivelu (2001), which is centered on an integrated language and content global awareness learning-what we call CLIGAL_-gives hope of developing thought and action-behavior as a 
skill set for creative excellence in higher education in Japan or anywhere else. More importantly perhaps the implementation of a practical, possible, purposeful, and particularly contextual CLIGAL gives hope of the university in Japan living with and helping students to live with and revel in uncertainty as Barnett has argued.

The main messages thus far that we offer involving creativity and excellence in education are:

a) creativity is about generating ideas or producing things and then transforming them into something of value which involves being inventive, ingenious, innovative, and (not only in an economic sense) entrepreneurial;

b) creativity is not about specific people or special people doing special things whether in thought and or in action; everyone has the potential to be creative, and creativity itself is a composite skill that needs to be developed in education;

c) creativity is an increasingly valuable commodity and state of being and becoming in the modern world;

d) creativity involves growth in how we see ourselves, our relations and relationships with others and groups of others, and also growth in how we view the world both immediate and more distant in terms of time and place;

e) creativity in thought is akin to rethinking one's own thinking and an embrace of lateral and divergent thought and thought processes, two modes of thinking that traditional schooling has not (fully) embraced;

f) creativity embraces both hard and soft thinking; the power of creativity is unleashed when both hemispheres of the brain combine to apply generative and evaluative processes, and perhaps most crucially;

g) the forming of collaborative, creative groups and partnerships best helps to foster (excellence) in creativity.

We will continue the discussion in part II looking more closely at the role and responsibility and usefulness of how to view higher education in Japan, particularly from the standpoint of language-culture-communication study that "begs to be" integrated with knowledge-content-and cognition study. In particular we will argue for a one-world philosophy for thought (Splitter, 1995; Bollinger et al., 2003) ontology of higher learning that explicitly connects that which we (can and want to) know about the world, and our communication about the world and its many subjects in the here and now.

In part III, we will argue for a renewed commitment to and enhanced (re)valuation of both liberal higher education, and the role and responsibility of (integrated and connected) language education across the university curriculum as part and parcel of liberal-general education. Our argumentation in part III includes advocating a higher education thought development privileging what Readings (1996) calls "dissenseus" and what Davies (2001) labels deviance. We will conclude part III by expounding on a values-laden phronetic creativity thought development following Flyvbjerg (2001) who advocates a social science learning centered on the questions of where we are and where we are headed.

We will conclude the discussion of creative excellence at the Japanese university in part IV by describing a post-method pedagogy-learning we call CLIGAL or content-language integrated global awareness higher learning. In our advocacy of and for CLIGAL we will hope to make more clear a contextually sensitive and practical and possible purposeful educating means of developing ten crucial dispositions in students at the university in Japan, as well as in ourselves, which taken together we believe can lead to more excellence in creativity in higher educating.

These ten dispositions and creativity learning principles are:

1) ensuring that teaching and its planning incorporates a flexible range of styles geared to rethinking our and students' thinking and behavioral practices;

2) providing opportunities for students, and for ourselves, to be involved in hands-on experimentation, problem-posing and problem-solving, and both individual and collaborative thought and discussion;

3) creating of opportunities where students actively think and work, and where they can more comfortably question what is going on and why;

4) sharing our teaching and learning intentions and aims with students, and providing them with numerous opportunities for choosing what why and how they study;

5) encouraging students to experiment, take chances, and think outside the box, and rewarding them for doing so;

6) joining in with students and modeling to and for students a variety of creativity-development dispositions in thought and behavior;

7) actively encouraging students to be inquisitive, make connections where and when possible, and explore ideas thru, for example, brainstorming, or thinking hats activities;

8) encouraging students to individually and collaboratively develop criteria they can use to evaluate their in- 
dividual and communal learning, and in particular how original and valuable their learning and their work is;

9) facilitating open discussion of any problems or concerns that students might be facing and how they can constructively approach and solve them, and lastly;

10) making effective and continual use of encouragement, praise and positive language, while at the same time using so-called failure or setbacks as further opportunities to learn and be creative.

\section{Higher Education in Japan and Where Is It (Headed): A One-World Philosophy for Thought to the Rescue}

Many universities in Japan have implemented policies, and both planned for and put into practice, programs of study which to some extent integrate the language-culture-communication and knowledge-content-cognition provisions of the curriculum. Most of these universities espouse and (attempt to) practice "global jinzai" and aim for greater excellence (and creativity?) as it and they relate to the development in students of a more connected and broadened global literacy, inclusive of being able to think and learn in more than the home L1 Japanese. Other universities, including where the two writers work, are ambivalent and confused about how to respond to the emergent global realities of higher education. At these institutions language-culture-communication higher learning is an end in and of itself. Worse, students in departments of study at these institutions, have very few or no opportunities to develop a more integrated connected creative thought skill set in both the local and an additionally useful global language at one and the same time.

Even if departments of study in these higher education institutions (HEI) do offer general and or specialized knowledge-content-cognition courses in an additional language, this is being done ad-hoc and piecemeal. There remains little if any conceptualization that culture-communication-language and knowledge-content-cognition study requires (1) integrated structures and integrated higher education institution (HEI) specialist-practitioners, and (2) the necessary mindsets and behavior of faculty-teachers to be both language and content practitioners at the same time, or at the very least have these two groups of faculty work more closely together, which is in our observations at our HEI not the case.

CLIGAL is a variant of what is known as CLIL (content and language integrated learning) first developed in Europe more than 20 years ago, and now spreading widely throughout the world including Asia and Japan. CLIGAL is an attempt towards creative excellence in teaching, learning, and research at the tertiary level of education, and seeks to help an institution develop the ways and means of embracing and practicing second order change as opposed to first order "cosmetic" change. CLIGAL critically involves change that goes to the core of what the educational institution believes and values. Does the HEI believe that simply changing course names and offerings, having all of its L2 language-communication-culture study centralized in a language center, or starting up a new department focusing on international studies equates with second order change? Does the institution (continue to) believe in and practice separate(d) collection or composite integration higher learning across the entire curriculum? Or does the institution believe in an integrated curriculum all parts being complementary to other parts?

CLIL and CLIGAL, both of which we will discuss in more depth in part IV of this paper, are conceptualizations and practices of and in higher education which value a non-separate(d) one world philosophy for creative thought higher learning. The conceptualization and implementation of CLIL-CLIGAL is, as was recognized 15 years ago by the Japanese Prime Minster's Commission on 21st Century Goals in and for Japan, absolutely vital to the survival of creatively excellent higher education in Japan.

According to De Courcy (2015) higher education is in a time of great change. Few people in the know would disagree. She says that universities are being increasingly pressured to demonstrate their value under increasing economic restraints and changing management and accountability structures, which is also the case at the two writer's HEI. Additionally, universities, maintains De Courcy are being pressured to demonstrate—not simply espouse-excellence in teaching and student/learning outcomes. De Courcy notes that,

external pressures have always influenced the working lives of faculty... and a number of global trends have impacted and, some would say, changed the role and working conditions of faculty. There is little debate that teaching and learning in the $21^{\text {st }}$ century requires a very different set of skills (p. 2).

What skills do excellent teachers need to now possess? Reviews of research in this area, says De Courcy, call for more clear definitions of higher quality (i.e. excellent) teaching and learning as well as support structures 
that would promote better teaching practices. Zhu, Wang, Cai, and Engels (2013) maintain it is not realistic to think that the current generation of students can benefit from traditional approaches to teaching and learning. Some models of better $21^{\text {st }}$ century teaching has excellent teachers characterized by their willingness and abilities to co-construct learning with students. Other models see an urgent need of excellent teachers to be socially competent able to communicate effectively to and with diverse groups of students.

Still other models prioritize a teacher's passion for his or her discipline(s), while technology competency requires the ability to integrate modern technology into practice. Fitzmaurice (2010) believes that,

... individual attributes of the teacher, their ability to deal with complex human interactions and relationships, a concern for 'weaker' students, a commitment to student-centred methodologies and a commitment to ongoing professional development are very much part of what it means to be an excellent teacher (p. 10).

Teaching in all these models described above is not solely an intellectual exercise; it is relational and according to De Courcy involves creating and maintaining caring physical, cultural, intellectual, social, and moral environments which taken together induce and enhance learning. De Courcy concludes her paper by noting that,

there is little research on faculty's perspectives on teaching excellence... what they find most useful for development and what they perceive as good indicators of performance... a study on teaching effectiveness in higher education in the $21^{\text {st }}$ century would be of great interest (p. 7).

Splitter (1995) argues that educational quality needs to be defined in terms of the thinking and feeling development of students so that they can feel free to create and explore. Schools, he says, are and continue to be agents of manipulation and preservers and protectors of the status quo. Most schools, confuse educating with a far more limiting economic-oriented view of training, a view supported by Weaver (1991), McVeigh (2002), Cutts (1997), and Refsing (1992). Splitter recognizes that the development of creative and critical thinking may not be welcomed by the wider society and in his words, "may be more of a threat than any priority" (p. 1). Splitter's philosophy for thought is a template for teachers and institutions whoever they are wherever they are to go beyond training and fitting students into what Weaver (1991) claims are extant systems of power and privilege.

Splitter advocates a Philosophy for Children and articulates six dispositions of that philosophy to guide educators in their teaching of creative and critical thinking as follows:

1) argumentation skills,

2) inquisitive skills, in particular searching for (sometimes hidden) reasons and not accepting what is offered or given without question,

3) identification, modification, and application of criteria to form judgments and make decisions,

4) making distinctions so as to be able to more clearly see the complexity of any situation, event, problem, or solution, act, or decision,

5) an ability to identify relationships (i.e. connect the dots) that help to make sense of things such as causes and effects, means and ends, parts and wholes, and

6) the exercising of moral imagination by which we think in different ways of proceeding (in thought and actions), and which represents to ourselves and others alternative moral-ethical positions and world views.

It is the larger questions of life that creative and critical-minded HEI and HEI teachers need to offer students as a realistic entry point into excellent creative thought, over and above transmitting uncritically what it or they or others think is or is not useful information, accepted opinions, or the such. These larger questions of life, which are not usually brought into the classroom, include:

a) who am I as an individual and member of society (i.e. social being)?

b) does my life (as an individual and social being) have a purpose beyond survival?

c) where did my/the world come from and where is it going?

d) what kind of world do I/we want to live in? and lastly

e) what does it mean to live well?

The language-culture-communication portion of a university's curriculum may be an ideal area in which to initiate a creative excellence higher study that aims to fulfill hopes of a philosophy for thought for children, and at the same time help ensure a more politically, socially, and culturally developed creative thought and action higher learning. Bollinger, Nainby, and Warren (2001) perceive a conceptual gulf between contemporary communication theory and practice, and critical education theory and practice. They also argue that at present there 
are two separate worlds of thought and study in education. One world is that world of socio-linguistic socio-cultural signifiers, the world humans communicate to each other with which is the entire set of symbols, sounds, gestures, pictures, words, and other things that we use to communicate. The second world is "things" we experience, we feel and think about, all the various things that we communicate about to and with one another. One important goal of education for Bollinger et al. is that teachers work with students to rethink and interrogate how and why we constitute the world as we do.

The prevalent and predominant representational two-worlds model, which is supported and condoned in Japanese higher education and its HEI by having knowledge-content-cognition and language-culture-communication in separate domains of education, fails miserably to account for the complexity of lived experiences of people (e.g. in classrooms) where the emphasis on learning remains fixated on systemic meanings rather than minute here-and-now communicative acts. Students need an ontological vocabulary, Bollinger et al. maintain, which will lend classroom study and educational practice a much greater sense of immediacy. They further argue this is crucial to having a creative, empowering, and emancipatory learning. A one-world ontology of study and learning integrates and connects "things out there in the world" and how we communicate about the world as we experience or imagine it.

Building on Freire (1972) and Stewart (1995), Bollinger et al. assert that human conditions are fully constituted in and through social interaction, and can be changed by social interaction as well. Two-world assumptions can and do adversely affect the exploration with students of the socially-constituted nature of, for example, control or exploitation. As a result two-world assumptions also affect any pedagogical possibilities to create the goal(s) of transforming exploitative pr controlling conditions. Communication, they argue, forms the essence of social life as it unifies humans and the world(s) in which people live. In other words language-communicationculture is not a mere instrumental tool as a means to achieving human world-shaping.

If we are to value higher education as an excellence in creativity enterprise, as a force that empowers, emancipates, and liberates young minds so that they can be free to create and explore, schools and faculties need to, argues Koliba (2000), teach students skills and dispositions to actively participate in a one-world philosophy for thought ontology of study and learning. These skills and dispositions must reflect criticality, creative, democratic, liberation principles and practices. More traditional (higher) education pedagogy relies on didactic authoritarian learning methodologies where teachers are "experts" in their disconnected fields with knowledge or language skills to impart to students uncritically. This teaches young people fundamental lessons about who they are and must be and about their passive roles in education and by inference in the wider society.

In part III after we give a brief overview of how higher education in our estimation has actually operated in Japan, we will argue for the necessity of re-valuing liberal education in HEI. In part III we will also look more closely at creative possibilities for language-culture-communication study in service to the development of creative excellence in higher education as it can focus what Littlejohn $(2001,2004)$ calls a "futures curriculum."

\section{4. (Re)Valuing Liberal and General Language-Communication-Culture Learning in a Phronetic-Wisdom Framework of Study}

Kumaravadivelu (2001) writes about the search for alternative organizing principles in language-culture-communication teaching and proposes a "post-method" pedagogy of particularity, possibility, and practicality. We would like to add the parameter of purposefulness to Kumaravadivelu's three parameters as we strongly believe that the purpose of any pedagogy-learning ought to include and involve the ongoing nurturing of creativity and creative thought and behavior in students' and teacher learning. Kumaravadivelu offers his three parameter pedagogical model as a response to what he considers to be "the repeatedly articulated dissatisfaction with the limitations of the concept of method and the transmission model of teacher education” (p. 537). His post-method pedagogy is a response to the over reliance on methods and methodology per se in the L2 (second language) profession that gives the L2 discipline its reason to exist.

What Kumaravadivelu says about dissatisfaction with the transmission model of education is applicable also to knowledge-content-cognition study. Unless a higher education first affirms the breadth and depth of intellectual thought, and is prioritized over specialized localized compartmental conceptions and practices of higher education learning wherever that learning occurs, there can be little if any hope of nurturing creativity across an integrated and connected curriculum. The implementation and practice of a creatively excellent higher education begins with the (re)valuation of liberal-general deep multidimensional thought development and must have con- 
textual possibility, particularity, and practicality as well as purposefulness.

McVeigh (2001, 2002) observes that higher education is Japan is a myth and states (2001: p. 29) that,

Japanese education is a paradox: Students sacrifice their youth to intensely prepare for all-important university entrance examinations, only to suddenly lose academic interest once they pass through the university gate. Commonly proposed meritorious explanations are inadequate. Any blame for apathy must ultimately be placed on the system rather than students themselves.

McVeigh maintains that in Japan's exam-centered education students are "socialized to associate study with preparation, classroom participation with ritualized inspection, test taking with catechism, academics with credentialism, and learning with monotonous training” (2001: p. 29). In the Japanese education system knowledge and content is disconnected, stored, and (re)packaged for later retrieval. Worse it is abstracted from immediate experience where knowledge loses much of its meaning as a body of information that points to something other than itself or oneself. Knowledge acquires, says McVeigh and others such as Cutts (1997), Refsing (1992), and Mosk and Nakata (1992), an overly practical and banal character in the Japanese university. Education is an exercise in perseverance in Japan sort of like jumping through hoops, injesting large amounts of often useless data which is necessary for one to become, for example, a bureaucrat.

In his discussion of the real purposes of education (2001) and higher education in particular (2002), McVeigh argues that critical creative exploratory thinking is not given enough time which he says "encourages a learning deficit” (2001: p. 31). Uninteresting and uninspiring teachers and instruction discourages students from (any) active participation. All these and other deficiencies are of course also influenced by Japanese culture in general such as "silence is golden," "the nail that sticks out get hammered down," and harmony is valued above all else. But it is undeniable that Japanese educational and university cultures contribute to this malaise.

McVeigh argues that the Japanese state or corporate culture also is deserving of much of the blame for the failings of universities where even the least ambitious and less than academically-inclined students still must endure the rigors of mental strain. McVeigh (2001: p. 31) states that,

Japan's universities are criticized as superfluous, pointless, and devoid of academic content as it no wonder that the primary goal of schooling is to socialize future workers for occupations in a hyper-rationalized, post-industrialized technologically-advanced capitalist economy.

The responsibility for this educating failure, which includes failure in developing students' excellence in creativity, is shared by the Japanese government, corporate Japan, and in particular university faculties. McVeigh argues that parents of university students and the wider society are also to blame. They uncritically continue to accept the certification and sorting functions of higher education where critical creative knowledge and content and cognition engagement through language-culture-communication study in both the L1 and additional L2 English is not a main goal. Why, asks McVeigh and others such as Refsing (1992), Cutts (1997), Readings (1996) and Brady, Abe, Takeda and Poole (2003), does it matter that Japanese higher education serves an educating purpose?

McVeigh answers that there are important cultural, social, and political issues that require creative thought which the typical tertiary-level school in Japan should inform its citizenry so that the Japanese citizenry can critically and creatively think about and act to seek out local and more global real-world problems and solve them. These would include, for example, racism, sexism, exclusionary policies, ethnocentrism, tensions in Japan's East Asia backyard and in the wider international neighborhood, environmental degradation including climate change, inequalities, and the Japanese nation's and its peoples' identity in the world. The lack of a critical thought and creative excellence in thought discourages young people from seeing and questioning shortcomings in their own and the wider world society. Students are also unchallenged to plan their own personal and professional goals.

Refsing (1992), Cutts (1997), Nakata and Mosk (1987), Brady et al. (2003), and McVeigh (2002) in particular, all contend that a pre-tertiary education in Japan is one where students have not been allowed the space or time to be themselves and "have been dissuaded from participating in their own schooling” (p. 9). Nakata and Mosk (1987) had observed that the Japanese labor force is one of the "best educated" in the world, yet McVeigh wonders, as we do, if "best education” applies to subjects such as language-communication-culture, history, social studies, and skill sets such as reasoning, critical analysis, or liberality of thought. What kind of education has the workforce received? The Japanese education system does a very capable job of training obedient and diligent 
citizen-workers who have a solid work ethic_-see Brady, Abe, Takeda, and Poole, 2003 for a more extended discussion. But young Japanese in the estimation of McVeigh and many others are ill-trained or uneducated (in general) in expressing themselves critically or with conviction arguing coherently.

Similar to those who have extensively researched the role and responsibility of higher education in Japan, Readings (1996) comes to the conclusion that at best faculty and higher educators must (re)think all that we (seek to) do as an opportunity for creative thought rather than any occasion for denunciation or mourning of the university and what it has stood for being in ruins. In our estimation dissensus or deviance is ultimately a rejection of a (1) separate(d) two worlds ontology of language-communication-culture and knowledge-content-cognition development, and (2) a dominant stultifying continued operational and transmission banking episteme education. The possibilities for both the present and the future of the university, whether in Japan or elsewhere, lie in the interaction and communication of individuals and collectivities in the here and now. A one-world philosophy for thought based on a reinvigorated liberal higher education that values dissensus and deviance in a values-laden phronetic study framework affirms the importance of full creative and critical exploratory thought and being in students' education.

A rebirth of liberal education in Japanese HEI and what it can offer students and young people is necessary in order to accomplish this redirection. Readings (1996) is of the opinion that we must recognize the university as a ruined institution where,

The University is not going to save the world by making the world more true, nor is or can the world save the University by making it more real (1997: p. 171).

Readings maintains (p. 166) that "in all probability far less will have changed in the daily life of professors and students than one might expect" but that "there are shifts taking place in HEI that are interruptive rather than linear." These shifts he labels "dereferentialization" which in his estimation has led to a marked decline in the ideological functions of higher education. He also wonders what the place of the university is in society, and what the shape of the university is as an institution.

Like McVeigh, Cutts, Refsing, Weaver, Mosk and Nakata et al., Readings is primarily concerned with privileging what he terms dissensus over consensus, or what Davies (2001) has termed "deviant thought.” It is not so important, Readings says, that we attempt through any reform or pedagogical approach to turn the university into a haven for thought, but that it is more realistic to focus on bringing thought back into the university where it has become more difficult and less and less necessary.

The "rebirth" of liberal higher education then is a key to creative excellence in HEI. Liberal education at any level, according to the Association of American Colleges \& Universities or AACU (2007),

Is an approach to learning that empowers individuals and prepares them to deal with complexity, diversity, and change. It provides students with broad knowledge of the wider world (e.g. science, culture, society) as well as in-depth study in a specific area of interest. A liberal education helps students develop a sense of social responsibility, as well as strong and transferable intellectual and practical skills such as (emphasis italics) communication, analytical problem-solving skills, and a demonstrated ability to apply knowledge and skills in real-world settings (p. 1).

It is clear then from what the AACU says that liberal education in the $21^{\text {st }}$ century involves intellectual and personal development, is a necessity for all students, and is essential for success in the global economy and for informed critical thought citizenship. The AACU argues that liberal education be across all fields of study. So why study the liberal arts, the humanities, sciences, the social sciences broadly, here in what is general education at Japanese HEI. HEI liberal-general education in Japan is being degraded, downgraded and is disappearing from many HEI curriculum provisions. It is also being marginalized at the expense of greater two-world ontology preferred disciplinary specialized faculty-driven study. According to Sigurdson (2015), a liberal arts education does not intend to train people for specific jobs. What it does do is prepare people for the world of workand leisure-by providing them with an invaluable set of employability and life-learning skills.

A liberal arts education is by nature broad and diverse, not specialized or narrow. Some think that the goals of a post-secondary education are to provide young people with as much specific training as possible before they go out in the working world as what is known in Japan as "shakaijin" or society people. In this view employers, including HEI, are relieved of any costs or risks associated with hiring so-called "untrained” workers. But what are some of the more potentially critical discrete skills, capacities, attributes or dispositions that are normally 
associated with liberal (arts) education? They would include, in Sigurdson's estimation:

1) evaluative and critical thinking skills,

2) creative thinking skills,

3) effective oral and written skills,

4) critical and reflective reading skills,

5) the ability to pose meaningful questions to advance one's knowledge and understanding(s),

6) the ability to conduct research and organize material(s) effectively,

7) the exercise of independent judgment(s) and ethical decision-making,

8) the ability to meet goals, manage time, and complete projects successfully,

9) the ability to cooperate with others and work in teams, and

10) a sensitivity to individuality and individual others and tolerance of cultural diversity and differences.

How many of the above and similar related skills, dispositions, and attributes could assuredly be "learned" or developed in a two-world ontology of study where language-communication-culture is separate(d) from and marginalized in relation to possibly uncritical "to be banked" knowledge and content? One might also wonder whether a liberal (arts) education makes for a happier healthier existence, and or makes one a better (i.e. more excellent) person? A liberal (arts) one-world philosophy for thought study may help one to perceive self, and to understand better one's shortcomings, which taken together allow a person to be a more excellent citizen, friend, spouse, parent, human being. Liberal (arts) courses, argues Sigurdson, enable students to reach beyond their own experiences and "imagine worlds far distant in time and space and can strengthen in people the virtues of tolerance, empathy, and respect for others" (p. 3).

It may be that this kind of learned one-world philosophy for thought and knowledge can and will make one wiser, better, more excellent. It is less assured that a two-world "collection of courses" curriculum that focuses on specialized disciplinary knowledge perhaps transmitted uncritically, and which students must bank for future use as trained workers, can do so. Hepner (2013) argues that higher education needs to throw out textbooks and specialized knowledge and replace them with primary sources. He adds that faculty need to begin communicating with their students instead of talking (down?) to them. A pseudo-intellectualism he says, can be fostered in an environment that "harbors" poor quality courses in which students are simply told what to think instead of how to think and search for truths" (p. 3)

There is a fundamental misunderstanding of the role and responsibility that language learning should play in higher education, argues Guillen (2009). From the perspective of teaching and researching the social sciences and sociology he strongly advises that this misunderstanding "could seriously imperil the ability of the university to educate students in the $21^{\text {st }}$ century” (p. 1). He recognizes, as do many others such as Littlejohn (2001), Crystal (1997, 2003), Bollinger et al. (2001), and Brady and Shinohara (2000, 2003), that language study is not simply helpful as a tool to achieve some end, as for example, pass a Test of English for International Communication (TOEIC), or get a job. Learning language(s) involves, as we have argued throughout this paper, culture and communication study and development, and needs to be studied within the context of critical and creative knowledge-content-cognition development.

Learning a language exercises the mind and enriches the spirit, and is a humbling experience by which students can learn that their culture and their way(s) of thinking and doing things and expressing themselves are relative, not absolute (Guillen, 2009: p. 3).

In part IV we will describe in some detail our conceptualization of CLIGAL as a post-method one-world philosophy for thought and values-laden higher learning. We believe that this variant of CLIL is best placed to effect an explicit integration of the two separate(d) worlds of higher education that being separated, blocks efforts at the excellently creative development of higher learning and higher person.

\section{CLIGAL as Post-Method Pedagogical Learning Serving the Development of Excellence in Creativity}

CLIL, or content and language integrated learning, is now a buzzword for English language teaching around the world including here in Asia and Japan. It is an umbrella term for the teaching and learning of language and content simultaneously, and covers a range of interpretations and possibilities. CLIL in any of its interpretations, however, means learning through the medium of English, not learning English as an end in itself. Language is 
used to communicate ideas, not for example, learning academically about the language’s history, grammar, lexicon, or sound system. It has proved particularly motivating for younger learners while it also enhances subject learning and the acquisition of the language that is to be used as the teaching and study medium of communication, culture, content, and cognition, the 4Cs of CLIL.

One of the main difficulties in applying CLIL systemically is to find qualified and academically competent knowledge-content-cognition subject teachers who are also trained language teachers. It is reported that only one national educational system which employs CLIL (Hungary) requires its CLIL teachers to give evidence of both subject and language teaching qualifications. In Japan, for example, CLIL has been led by language teachers who may, but usually do not, have knowledge or expertise with subject study. From observations and having researched a number of HEI including the writers' own HEI, it is rare that knowledge-content-cognition faculty lead or have qualifications to lead a CLIL, or even have any interest in leading a university CLIL. The great majority of specialist content faculty at HEI in Japan have not had any formal training in language teaching, though some or many-depending on the particular institution or specialty-area study department—can converse in English or do in their research in English, and some indeed often write academic papers in English.

In Japan in this age of "global jinzai" and the internationalization and globalization of higher education, English-language medium learning in HEI known as EMI or English medium instruction, is seemingly the preferred alternative to any conception planning or practice of CLIL. Unfortunately, given the fact that there is little or no language-culture-communication mission built into the globalized specialty-area curriculum at HEI in Japan, EMI can be taught by English-conversant English-research literate HEI faculty even though they may have little if any expertise in teaching culturally or communicatively in a language (English) that is not their own mother tongue. This is especially true at the writers' HEI where only 5\% - 6\% of the faculty operate in English and many of them are hired as English language teachers. Some universities in Japan, including the one where the writers work, employ a small number of "native speaker” faculty to teach subjects in English, either full-time but more prevalently contract or adjunct faculty, but these HEI faculty in most cases have little if any expertise in language-culture-communication teaching.

Alternatively, some universities are planning and attempting to implement programs of EMI study utilizing English language teachers, but these teachers as a whole have little if any subject knowledge-content-cognition teaching experience in the subject (for example, sociology or economics or political science) that would more ideally qualify them as CLIL or CLIL-type teachers. In short and in general, in Japan at HEI, EMI, not CLIL, is preferred and has been conceived, planned, implemented and practiced as a new way of dealing with the shortcomings of the (separated and marginalized) language-culture-communication curriculum. EMI thus seeks to alter ways in which language-culture-communication teaching and learning can be conceptualized or practiced, with little if any concern for effecting a concerted one-world philosophy for thought integration.

We are thus left with a situation at the meso-macro level at HEI where, on the one hand, content is to some degree being delivered in an additional (English) language by faculty but who are not English language specialists. On the other hand, additional (English) language faculty who are so inclined and or motivated personally or institutionally to teach subject knowledge-content-cognition in general or specialized fields of higher study, are leading the charge so to speak with EMI. The growth and spread of EMI in Japan as reported by Brady and Higgins (2014) is linked to broader concerns in Japanese higher education such as educational reform, global competitiveness, institutional sustainability and viability, and also as a response to the criticism that Japanese higher education is a closed system. The goals of an EMI for its primary stakeholders — students, teachers, the wider society-have yet to be investigated or determined. Teachers and students in an uncritical and to some degree ad-hoc EMI are greatly challenged to make adjustments in the manner in which teaching and learning is initiated and carried on and progresses.

If it is accepted that EMI or EAP (English for Academic Purposes) has goals that go beyond simply using an L2 in subject learning, and that EMI-EAP ought to help students improve critical creative thinking and intercultural learning skills in addition to improving their knowledge and use of English, then any systemic EMI program conceptualized, planned, or implemented (our emphasis) will crucially require cooperation and collaboration from the two-worlds of academia: language-culture-communication, and (specialty-area) subject knowledge-content-cognition.

To effect such second order change amidst the many challenges and obstacles that exist within socio-cultures at HEI in Japan is daunting to say the least. When it becomes extremely difficult if not impossible to meet these challenges head on and circumvent obstacles to integration, collaboration, and cooperation among the storied 
cliques of HEI faculty, it will be necessary to institute, however possible EMI-EAP, or more advantageously CLIL-CLIGAl, initially on a micro-level class basis. Doing so can solve a number of important needs of higher education to serve its emerging global citizenry and meet the concerns of the Japanese Prime Minister's Commission (2000-01) on Japan's Goals in the $21^{\text {st }}$ Century. The primary stakeholders, citizen-students and faculty working together in the classroom, are involved and invested from the start in determining the what, why, and how of integrated one-world philosophy for creative thought study.

If it be the case that classroom practitioners, from whatever discipline whether language or content-oriented, have themselves interest in and academic and educational expertise and experience in teaching a one-world integrated philosophy for values and wisdom learning study, a quality goals-oriented EMI-EAP-CLIL-CLIGAL can be initiated from bottom-up rather than top-down, which is usually the case in Japan at HEI reports Dearden (2014). Dearden observes that in many national societies and at many HEI in those societies, the educational infrastructure does not, in fact may not wish to, support any quality planning, implementation, or practice of an EAP-EMI or CLIL. Where does this leave those HEI in Japan that do wish to have an integrated one-world philosophy for critical creative thought development across their specialty and liberal-general education curricu$\operatorname{lum}(\mathrm{s})$ ?

It is here that CLIGAL becomes most relevant. CLIL and CLIGAL privilege those skills, dispositions, and attributes of a creative learning that will be necessary to save Japan and its HEI from itself and themselves. The 4Cs of CLIL-CLIGAL are, to repeat: communication, cognition, culture, and content. This in itself qualifies CLIL-CLIGAL as a choice post-method pedagogy of particularity, possibility, practicality, and purposefulness to serve those interests in Japan and its society who value the future global and international vitality and vibrancy and viability of this nation and its citizenry.

We are not in this paper arguing for an uncritical "across-the-board" universal planning or implementation of CLIL or CLIGAL in Japan at its HEI. We are arguing that in response to the 2000-2001 Prime Minister's Commission call, those HEI which are willing and able to challenge their core cultural thinking and practices, and to honestly determine whether that thinking and those practices match the future global needs of Japan, should sooner than later employ faculty who are integrated 4Cs specialists. They further need to set up and strengthen institutional structures that will allow these faculty to practice a 4Cs one-world philosophy for creative thought phronetic higher teaching and learning.

CLIL and CLIGAL can serve usefully as an impetus within HEI in Japan to breaking down barriers and obstacles to an integrated 4Cs curriculum. CLIL-CLIGAL can help an institution and its faculty practitioners to adjust and when necessary transform its and their socio-cultural, socio-political, and socio-economic structures and practices (agency) to serve the global awareness and global engagement needs of Japan and its citizenry. CLIL-CLIGAL thus is an enabler of the kind of second order change(s) that are necessary and have been voiced here in Japan as well as outside Japan for many years now for its people and its institutions to question their thinking and practices, in short to be locally and globally creatively excellent in its and their thought and actions. There is a real need for Japan and its educational system and practices to "open up.” The present and future vibrancy of the Japanese nation-state and its citizenry rests on its and their abilities to think and act creatively and constructively both on a local and international-global level. It is the interaction of people in communication that gives credence to excellence in creativity.

\section{Concluding Remarks}

We have defined and argued for creative excellence in higher education in Japan as liberality of thought, feeling, and agency of teachers working with students in a one-world philosophy for phronetic values-laden thought and wisdom development of study and person. Creative excellence in higher education across the entire curriculum begins with a reunion and re-integration of the two now higher education in Japan disparate worlds of languagecommunication-culture and knowledge-content-cognition. CLIL or CLIGAL is ideally placed as a post-method 4Ps (particularity-context, possibility, practicality, purposefulness) 4Cs (content, culture, cognition, communication) creative excellence approach that binds teachers and students together in search of individual and mutual intellectual, affective, and personal growth, not in service solely to themselves, but which helps their society to be more globally aware and connected with the world.

Creative excellence in higher education also begins with a clear(er) recognition of the importance of liberalgeneral education, and in particular language study as an important, perhaps the most important, part of that 
education. Language-culture-communication study needs to be recognized as an important means to the coconstruction of knowledge and the development of cognition and emotional intelligence in every study area in higher education. A 4Ps sustainable excellence in creativity higher education crucially depends on realistically, practically, and purposefully re-connecting language and content in a connected one-world paradigm of higher study, and this requires a re-valuation of language-communication-culture teaching as the most valuable component of a higher education.

Language-communication-culture study does not exist in a vacuum (Calvet, 1998), as is unfortunately the case at the two writers' HEI. The study of and in language(s) is an important and valuable means to wisdom learning. The practice of creative excellence in higher education is rooted in the humanistic philosophy that affirms that all individuals have creative potential (Chen-Tsai, 2013). Burnard (2012) emphasizes the role of teachers as agents who catalyze this process of change, which requires of teachers a high level of professionalism and expertise. In our estimation this professionalism and expertise must be in both interconnected worlds of study, language-culture-communication, and knowledge-content-cognition. Chen-Tsai reports that in a number of studies several salient characteristics of creative teachers and teaching have been clearly identified such as curiosity, risk-taking, open-mindedness, humor, independence, self-confidence, flexibility, and aesthetic orientation.

Burnard (2012) suggests that the above and related characteristics are "deeply connected to thinking styles which include visualization, experimentation, imagination, reflection, analysis, synthesis, metaphorical thinking, and evaluation” (p. 68). Teachers play a pivotal role in helping shape students' learning. Regarding the development of creativity in the classroom, they can condition or impede creativity through their teaching, but also through the manner in which they communicate with their students and be creative themselves in that process. Jeffrey (2006) notes that there are three things that directly point to teachers who are creative: they are innovative, they enjoyed the process of study interaction, and they invested time in their communication and discussions with their students.

What can a creatively-minded teacher and institution do to excellently condition the development of higher learning creativity? Rinkevich (2011) has recommended a number of creative teaching and learning strategies: (1) provoking unorthodox thinking, (2) beginning class with an announcement of a fact of the day to promote lifelong learning, (3) incorporating the total environment both inside and outside the classroom to the one-world learning space so as to encourage students to explore the world around them, and (4) providing autonomous learning opportunities to develop students' (and teachers') strengths and interests. Developing creativity is not an extra task says Chen-Tsai, but is an essential capability for teachers, in our argued estimation, connected one-world ongoing professional development. Creativity is not limited to special or specific study areas whatever or wherever they might be, but can and needs to be integrated into all study provision areas.

Creativity, especially of the excellent variety, requires deep commitment, concentration, risk-taking, and personal and professional transformation from teachers, and their HEI. Creative education is not safe, and it can potentially be threatening to orthodox classroom management due to its nature of disruption, dissensus, deviancy, and inquisitiveness about the status quo. But its development is absolutely vital to the sustainability of Japanese society and in particular HEI which claim to serve the interests and needs of the wider society. Higher education can only be transformed into a higher and better creativity development, and thus improve its value as education for uncertainty, when it becomes more humanized.

University faculty, whether liberal-general language-communication-culture, or specialized knowledgecontent-cognition practitioners, cannot magically transform students into agents of creativity or criticality. The important thing is that as change and creativity agents themselves in their teaching, communication with students, and in their research with students, they exhibit and express an ethical code which students can also experience and then choose to absorb so as to transform themselves. Disciplines of higher education study when approached with full participation of students, within a democratizing and humanizing framework, can become excellently creative self-actualizing academic experiences for students and faculty alike, ultimately affecting also the creative excellence of the HEI itself.

Knowledge of and in, for example, (the) sociology (department) or (the) language (center) is not "out there" to be discovered, packaged and retrieved for later use. It is also neither objective nor impersonal. It is the $21^{\text {st }}$ century responsibility of HEI faculty to individually and collaboratively recast knowledge transmission and co-construction into cultural, cognitive, and communicative relevance for students. Included within this responsibility of faculty is a mission to recast communication and culture and cognitive study into a practical and socially responsible knowledge base for life learning. 


\section{References}

Association of American Colleges and Universities (2007). What Is a 21 $1^{\text {st }}$ Century Liberal Education? Adapted from College Learning for the New Global Century.

Barnett, R. (1997). Realizing the University in an Age of Supercomplexity. Buckingham: Open University Press/SRHE.

Bollinger, C., Nainby, K., \& Warren, J. (2003). Articulating Contact in the Classroom: Towards a Constitutive Focus in Critical Pedagogy. Language and Intercultural Communication, 3, 198-212. http://dx.doi.org/10.1080/14708470308668105

Brady, A., \& Higgins, R. M. (2014). Internationalization, Globalization, Regionalization, and Academic Mobility: Educational Threats and Opportunities to the Development of a Global-Minded Citizenry. Kwansei Gakuin Sociology Department Studies, 119, 55-66.

Brady, A., \& Shinohara, Y. (2000). Principles and Activities That Exemplify a Transcultural Approach to Additional Language Learning. System, 28, 305-322. http://dx.doi.org/10.1016/S0346-251X(00)00014-2

Brady, A., \& Shinohara, Y. (2003). English Additional Language Learning and Empowerment: Conceiving and Practicing a Transcultural Pedagogy and Learning. Asian Journal of English Language Teaching, 13, 75-93.

Brady, A., Abe, K., Takeda, J., \& Poole, B. (2003). Towards a Clearer Understanding of the Socio-Economic, Socio-Educational, and Socio-Political Role of Higher Education in Japan. Kwansei Gakuin University Sociology Department Studies, 95, 95-106.

Burnard, P. (2012). Rethinking Creative Teaching and Teaching as Research: Mapping the Critical Phases That Mark Times of Change and Choosing as Learners and Teachers of Music. Theory into Practice, 51, 167-178. http://dx.doi.org/10.1080/00405841.2012.690312

Calvet, J. (1998). Language Wars and Linguistic Politics. Oxford: Oxford University Press.

Chen-Tsai, K. (2013). Creative Teaching and Teaching Excellence. In F. K. Reisman (Ed.), Creativity Process, Product, Personality, Environment \& Technology (pp. 131-139). KIE Conference Book Series.

Crystal, D. (1997). English as a Global Language. Cambridge: Cambridge University Press.

Cutts, R. L. (1997). An Empire of Schools: Japan's Universities and the Molding of a National Power Elite. Armonk, NY: M.E. Sharpe Press.

Davies, L. (2001). Development, Democracy, and Deviance in Contemporary Sociology of Education. In J. Demaine (Ed.), Sociology of Education Today. Houndmills and Basingstoke: Palgrave Press.

De Bono, E. (1982). De Bono's Course in Thinking. BBC Books.

De Courcy, E. (2015). Defining and Measuring Teaching Excellence in Higher Education in the $21^{\text {st }}$ Century. College Quarterly, 18.

Dearden, J. (2014). English as a Medium of Instruction-A Growing Global Phenomenon: Phase 1. Going Global 2014, Interim Report, Oxford: Department of Education, University of Oxford.

Fitzmaurice, M. (2010). Considering Teaching in Higher Education as a Practice. Teaching in Higher Education, 15, 45-55. http://dx.doi.org/10.1080/13562510903487941

Flyvbjerg, B. (2001). Making Social Science Matter: Why Social Inquiry Fails and How It Can Succeed Again. Cambridge: Cambridge University Press. http://dx.doi.org/10.1017/CBO9780511810503

Freire, P. (1972). Pedagogy of the Oppressed. London: Penguin Books.

Gardner, H. (2009). Five Minds for the Future. Boston, MA: Harvard Business School Press.

Gottlieb, M. (2014). The Confounding Case of Japan’s Creativity Crisis. Japan Times Article, January 29.

Guillen, M. F. (2009). The Real Reasons to Support Language Study. The Chronicle of Higher Education, 1-4.

Hepner, M. (2013). Good Thing I'm Not a History Major. Real Clear Politics.

Japan Times (2007). Japan’s Ambivalent English. Opinion-Editorial, March 3.

Jeffrey, B. (2006). Creative Teaching and Learning: Towards a Common Discourse and Practice. Cambridge Journal of Education, 36, 399-414. http://dx.doi.org/10.1080/03057640600866015

Kao, J. J. (1996). Jamming: Art and Discipline of Corporate Creativity. New York: Harper Collins.

Keidanren (2013). Fostering People Who Can Excel in Global Arena-A Follow-Up Proposal for the Development of Global Talents. Keidanren Paper, June 13.

Koliba, C. (2000). Democracy and Education, Schools and Communities Initiative: Conceptual Framework and Preliminary Findings. Cambridge: Cambridge University Press.

Kumaravadivelu, B. (2001). Toward a Postmethod Pedagogy. TESOL Quarterly, 35, 537-557.

http://dx.doi.org/10.2307/3588427 
Littlejohn, A. (2004). Language Teaching for the Future. Cambridge Connection, Japan Special Edition, 2-3.

McVeigh, B. (2001). Higher Education, Apathy, and Post-Meritocracy. The Language Teacher, 25, 29-32.

McVeigh, B. (2002). Japanese Higher Education as Myth. New York and London: M. E. Sharpe.

Nakata, Y., \& Mosk, C. (1987). The Demand for College Education in Postwar Japan. Journal of Human Resources, 22, 377-404. http://dx.doi.org/10.2307/145745

Prime Minister's Commission on Japan's Goals for the 21st Century (2000) National Science Foundation.

Readings, B. (1996). The University in Ruins. Boston, MA: Harvard University Press.

Refsing, K. (1992). Japanese Educational Expansion: Quality or Equality? In R. Goodman, \& K. Refsing (Eds.), Ideology and Practice in Modern Japan (pp. 116-129). New York: Routledge Press.

Rinkevich, J. R. (2011). Creative Teaching: Why It Matters and Where to Begin. Clearing House, 84, 219-223. http://dx.doi.org/10.1080/00098655.2011.575416

Robinson, K. (2009). Why Creativity Now? Teaching for the 21st Century, 67, 22-26.

Seidlhofer, B. (2005). English as a Lingua Franca. ELT Journal, 59, 339-341. http://dx.doi.org/10.1093/elt/cci064

Sigurdson, R. (2015). Why Study the Liberal Arts. Manitoba: University of Manitoba.

Splitter, L. J. (1995). On the Theme of "Teaching for Higher Order Skills.” http://www.Shss.Montclair.edu/inquiry/summ95/splitter.html

Stewart, J. (1995). Language as Articulate Contact: Toward a Post-Semiotic Philosophy of Education. Albany, NY: SUNY Press.

Van Oech, R. (1990). Fostering Creativity: The Journey to Excellence. http://www.journeytoexcellence.org.uk/resourcesandcpd/research/summaries/rsfosteringcreativity.asp

Vygotsky, L. S. (2004). Imagination and Creativity in Childhood. Journal of Russian and East European Psychology, 42, 797.

Weaver, F. S. (1991). Liberal Education: Critical Essays on Professions, Pedagogy, and Structure. New York/London: Teachers' College Press (Columbia University).

Zhu, C., Wang, D., Cai, Y., \& Engels, N. (2013). What Core Competencies Are Related to Teachers' Innovative Teaching? Asia-Pacific Journal of Teacher Education, 41, 9-27. 